\title{
Standard deviation of absolute and differential pressure fluctuations in fluidized beds of group B particles
}

\author{
C. Sobrino, S. Sánchez-Delgado, N. García-Hernando, M. de Vega* \\ Ingeniería de Sistemas Energéticos (ISE) Reseach Group, Departamento de Ingeniería Térmica y de Fluidos, \\ Universidad Carlos III de Madrid, Auda. De la Universidad 30, 28911 Leganés, Madrid, Spain
}

\begin{abstract}
A B S T R A C T
This work describes the behaviour of the standard deviation of pressure fluctuations, $\sigma$, in fluidized beds for group B particles in the bubbling regime. An empirical-theoretical function, which depends on the gas velocity, is proposed for predicting the pressure signal fluctuations, and the corresponding values of $\sigma$ are calculated. The differences in the standard deviation of pressure fluctuations obtained for absolute or differential sensors are analyzed and compared to experimental values corresponding to different bed dimensions, pressure probe positions and particle properties.
\end{abstract}

Keywords: Fluidization; Gas-solid bed; Pressure fluctuations

\section{Introduction}

Knowledge of bed fluctuations in a gas-solid fluidized bed is important for its design and/or operation as they provide information on indexes of fluidization quality, which include formation, rise and eruption of gas bubbles, movement of solids and pressure waves propagation through the bed. These indexes are commonly considered as an indicative of the dynamic behaviour of the fluidized bed and can be explored as a way of monitoring the process (Felipe and Rocha, 2007). Due to the ease of measurement and its significance in understanding dynamic behaviours, pressure time series and pressure fluctuations have been investigated by numerous researchers $(\mathrm{Bi}, 2007)$. It is accepted that the complex pressure signal is a result of the superposition of local fluctuations caused mainly by traveling gas bubbles and fast-traveling pressure waves arising due to bubble formation, coalescence and eruption. In order to characterize the hydrodynamics of the bed, statistical methods and spectral analysis have been used to identify these phenomena and to establish the different fluidization regimes (Lirag and Littman, 1971; Fan et al., 1981; Johnsson et al., 2000; van der Schaaf et al., 2002; Bai et al., 2005; Puncochar and Drahos, 2005). A simple statistical parameter, the standard deviation of pressure fluctuations, is commonly used to determine the minimum fluidization veloc- ity (Puncochar et al., 1985; Wilkinson, 1995; Felipe and Rocha, 2007).

In spite of the measurement simplicity the nature of pressure fluctuations in a fluidized bed is a complex function of particle properties, bed geometry, flow conditions, pressure and temperature. Fan et al. (1981) investigated the effect of particle size, static bed height and gas velocity. Svoboda et al. (1984) showed that the magnitude of the pressure fluctuations increases with both excess gas velocity and particle diameter. Svoboda et al. (1983) also reported that the amplitude of pressure fluctuations depends upon the height above the distributor. Pressure fluctuations can be very different at different locations on the axis of the bed (the region of bubble coalescence is displaced as the gas velocity increases) and thus the position at which pressure fluctuations are measured becomes an important factor in determining the relationship between the standard deviation of pressure fluctuations and the gas velocity. The effect of the probe location was studied by Hong et al. (1990) and Wilkinson (1995) for several particle sizes and static bed heights. The use of absolute or differential probes has also been discussed in order to elucidate weather or not they provide similar or different information: Roy and Davidson (1989) showed that single point pressure measurements were different from differential pressure measurements because the former included contributions from all

\footnotetext{
* Corresponding author. Fax: +34916249430.

E-mail address: mdevega@ing.uc3m.es (M. de Vega).

Received 26 February 2008; Received in revised form 19 June 2008; Accepted 25 June 2008

0263-8762/\$ - see front matter () 2008 The Institution of Chemical Engineers. Published by Elsevier B.V. All rights reserved. doi:10.1016/j.cherd.2008.06.006
} 


\author{
Nomenclature \\ A amplitude $(\mathrm{Pa})$ \\ $A_{0} \quad$ distributor area per number of holes $\left(\mathrm{m}^{2}\right)$ \\ $d_{\mathrm{p}} \quad$ particle diameter $(\mathrm{m})$ \\ $D_{\mathrm{B}} \quad$ bubble diameter $(\mathrm{m})$ \\ $f \quad$ frequency $(\mathrm{Hz})$ \\ $\mathrm{H} \quad$ bed height $(\mathrm{m})$ \\ $k$ proportionality factor in Eq. (6) \\ $P_{B} \quad$ fluctuating component of absolute pressure \\ due to bubble $(\mathrm{Pa})$ \\ $P_{f} \quad$ fluctuating component of absolute pressure \\ (Pa) \\ $P_{\text {signal }} \quad$ pressure signal $(\mathrm{Pa})$ \\ $\mathrm{P}_{\mathrm{W}} \quad$ fluctuating component of absolute pressure \\ due to oscillating bed $(\mathrm{Pa})$ \\ $\triangle P \quad$ pressure drop $(\mathrm{Pa})$ \\ $\mathrm{R}_{\mathrm{B}} \quad$ bubble radius $(\mathrm{m})$ \\ $t \quad$ time $(\mathrm{s})$ \\ U gas velocity $(\mathrm{m} / \mathrm{s})$ \\ $U_{B} \quad$ rise velocity of isolated bubble $(\mathrm{m} / \mathrm{s})$ \\ $U_{\mathrm{mf}} \quad$ minimum fluidization velocity $(\mathrm{m} / \mathrm{s})$ \\ $z \quad$ height position in the bed (m) \\ Greek letters \\ $\varepsilon \quad$ voidage \\ $\rho_{\mathrm{p}} \quad$ particle density $\left(\mathrm{kg} / \mathrm{m}^{3}\right)$ \\ $\sigma \quad$ standard deviation of pressure fluctuations $(\mathrm{Pa})$
}

sources while differential pressure mainly reflected pressure fluctuations across measurement interval.

The majority of the investigators agree upon the existence of a dominant frequency for the pressure fluctuations. This frequency has been shown to be related to the emergence of gas bubbles at the surface of the bed. Verloop and Heertjes (1974) reported that pressure fluctuations are similar to sinusoidal waves. Hiraoka et al. $(1984,1986)$ developed a dynamic model to predict the dominant frequency of bed fluctuations. Baskakov et al. (1986) and Alzahrani and Wali (1993) proposed correlations for predicting the amplitude and frequency of the pressure fluctuations. Chen and Bi (2003) developed a mechanistic model to simulate pressure fluctuations for group A particles with the aim of determining the transition to turbulent fluidization.

The aim of the present work is to describe the behaviour of the standard deviation of pressure fluctuations, $\sigma$, in fluidized beds for group B particles in the bubbling regime. A model for the pressure fluctuating signal is presented, taking into account the contribution of two different terms: the global absolute oscillation of the bed and the local passage of an ascending bubble. This simple model allows to understanding the differences found between $\sigma$ in absolute and differential pressure measurements. The results are analyzed and compared to experimental values, for different static bed heights, probe positions and particle properties.

\section{Model development}

Pressure fluctuations in gas-solid bubbling fluidized beds are a consequence of different phenomena: rising gas bubbles, bed mass oscillation, bubble coalescence, bubble eruption and gas turbulence. van der Schaaf et al. (2002) proposed a way to decompose the power spectral density of the pressure fluctuations into a component corresponding to global phenomena (the coherent part of the pressure signal) and a component corresponding to local phenomena (the incoherent part of the pressure signal). They assumed that all pressure waves caused by bubble coalescence, gas flow fluctuations, bubble eruption and bed mass oscillation could be measured almost instantaneously throughout the entire bed and also in the plenum; bubbles were assumed to be the only local phenomenon. This is reasonable for small fluidized beds (diameters below $0.5 \mathrm{~m}$ ).

When a gas bubble rising through the fluidized bed passes the measurement position a pressure fluctuation is generated with a characteristic shape. A model for the pressure fluctuation caused by a single rising bubble was proposed by Davidson and Harrison (1963). According to this model, the pressure distribution around a bubble of radius $R_{B}$ relative to that in the dense phase (at a great distance above or below the bubble) can be written as (Ramayya et al., 1996):

$P_{B}(t)=\rho_{P} g(1-\varepsilon) \frac{R_{B}^{3}}{r(t)^{2}} \cos \vartheta \quad$ for $r(t)>R_{B}$

$P_{B}(t)=\rho_{P} g(1-\varepsilon) r(t) \cos \vartheta \quad$ for $r(t)>R_{B}$

with the origin of the polar coordinate system at the bubble centre. In Eqs. (1) and (2) the distance $r(t)$ can be substituted by $r(t)=t \cdot U_{B}$ where $U_{B}$ is the rise velocity of an isolated bubble (Davidson and Harrison, 1963; Ramayya et al., 1996; Rowe and Masson, 1981): $U_{B}=0.71 \sqrt{g D_{B}}$.

In the present study, the term $\left(U-U_{m f}\right)$ generally added to $U_{B}$ to give a mean estimate for increases in velocity due to bubble interactions (Clift and Grace, 1985) is not considered, for the sake of simplicity.

The bubble diameter at a given height $\mathrm{z}$ measured from the distributor, $D_{B}=2 R_{B}$, can be calculated, for group $B$ particles by Darton's correlation (Darton et al., 1977):

$D_{B}=\frac{0.54\left(U-U_{m f}\right)^{0.4}\left(z+4 \sqrt{A_{0}}\right)^{0.8}}{g^{0.2}}$

where $A_{0}$ is the distributor area per number of holes.

The Davidson's model assumes an infinitely wide fluidized bed. However, according to van Ommen et al. (2004), for small diameter columns the effect of moving bed mass should be included.

When the bed is in the bubbling regime, waves originated at the bed surface due to the motion in the freeboard caused by the erupting bubbles can be sensed also in the plenum therefore they represent the oscillating bed global behaviour (van der Schaaf et al., 2002). Contrarily, rising bubbles generate local pressure fluctuations (Puncochar and Drahos, 2005; van der Schaaf et al., 2002). According to this, Bi (2007) proposed an expression for the fluctuating component of the signals from the absolute pressure measurement as

$P_{f}(t)=P_{W}(t)+P_{B}(t)$

In the present work, $P_{B}(t)$ represents the fluctuating component corresponding to bubble passage calculated according to Eqs. (1) and (2) and $P_{\mathrm{W}}(\mathrm{t})$ represents the fluctuating component caused by other sources. A sinusoidal function is proposed to describe $P_{W}(t)$ :

$P_{W}(t)=A \sin (2 \pi f t)$ 


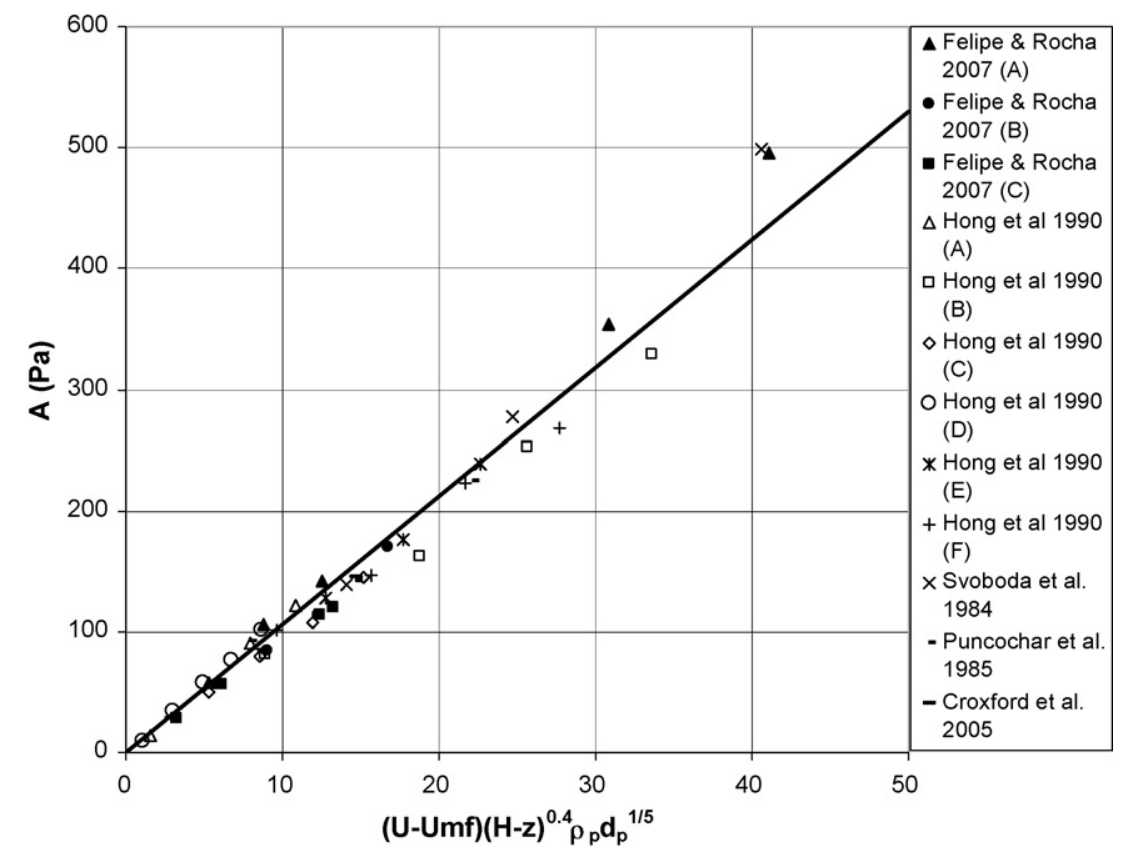

Fig. 1 - Amplitude of absolute pressure fluctuations.

The amplitude of the global fluctuation $A$ and its frequency $f$ are determined as follows.

\subsection{Main amplitude and frequency}

Many studies have reported before that the amplitude of pressure fluctuations is proportional to the superficial gas velocity. According to Puncochar and Drahos (2005), the standard deviation of pressure fluctuations depends on the density of the particles, the excess gas velocity and a constant of proportionality dependent on bed geometry and probe position. Baskakov et al. (1986) and Alzahrani and Wali (1993) reported that the amplitude of the fluctuations is directly proportional to $\Delta P^{0.42}$, where $\Delta P$ is the pressure drop. As the term $\Delta P$ is proportional to the distance between the probe ports and the bed surface, the amplitude can be considered proportional to $(\mathrm{H}-\mathrm{z})^{0.42}$.

Also Alzaharani and Wali (1993), using the empirical correlation developed by Talmor and Benenati (1963), established a relation between the pressure fluctuation amplitude and the particle diameter.

Provided the dependence of the amplitude of pressure fluctuations on these parameters, i.e. $A=f\left(U-U_{m f} ; \rho_{P} ;(H-z) ; d_{P}\right)$, an empirical correlation for the amplitude of pressure fluctuations has been adjusted using experimental data available in the literature. In Fig. 1 data of the amplitude of absolute pressure fluctuations from several studies are presented (Felipe and Rocha, 2007; Hong et al., 1990; Svoboda et al., 1984; Puncochar et al., 1985; Croxford et al., 2005). Table 1 shows the particle properties, bed static height and probe position from the distributor for each measurement in Fig. 1.

The measured amplitude corresponding to the experiments found in the literature are plotted in Fig. 1 together with the linear regression that fits the data.

The amplitude of the global pressure fluctuations $P_{\mathrm{w}}(t)$ in Eq. (5) is therefore represented by

$A=k\left(U-U_{\mathrm{mf}}\right)(H-z)^{0.4} \rho_{\mathrm{P}} d_{\mathrm{P}}{ }^{1 / 5}$

where $k$ is the adjusting linear coefficient, equal to 10.5 .

When spectral analysis of pressure signals in fluidized beds is applied, multiple peak frequencies can be identified. There is generally one with the highest power intensity in the power spectrum, which is usually identified as the dominant frequency. According to Bi (2007) most natural frequency equations in the literature agree reasonably well with the dominant frequency data. In the present model, the value of

\section{Table 1 - Particle density $\left(\rho_{\mathrm{P}}\right)$ and diameter $\left(d_{\mathrm{P}}\right)$, bed height $(H)$ and probe axial position $(z)$ for experiments in Fig. 1}

\begin{tabular}{|c|c|c|c|c|c|}
\hline Ref. & Series in Fig. 1 & $H(\mathrm{~cm})$ & $\mathrm{z}(\mathrm{cm})$ & $\rho_{\mathrm{P}}\left(\mathrm{kg} / \mathrm{m}^{3}\right)$ & $d_{\mathrm{P}}(\mu \mathrm{m})$ \\
\hline \multirow[t]{3}{*}{ Felipe and Rocha (2007) } & A & 22 & 15 & 2480 & 193 \\
\hline & B & 22 & 15 & 980 & 329 \\
\hline & C & 22 & 15 & 2720 & 106 \\
\hline \multirow[t]{6}{*}{ Hong et al. (1990) } & A & 11 & 10 & 2670 & 715 \\
\hline & B & 22 & 12.5 & 2670 & 715 \\
\hline & C & 11 & 7.5 & 2670 & 359 \\
\hline & D & 11 & 10 & 2670 & 359 \\
\hline & E & 16.3 & 12.5 & 2670 & 359 \\
\hline & $\mathrm{F}$ & 22 & 7.5 & 2670 & 359 \\
\hline Svoboda et al. (1984) & & 17 & 8.5 & 2220 & 565 \\
\hline Puncochar et al. (1985) & & 17 & 8.5 & 1680 & 90 \\
\hline Croxford et al. (2005) & & 46 & 10 & 2600 & 159 \\
\hline
\end{tabular}



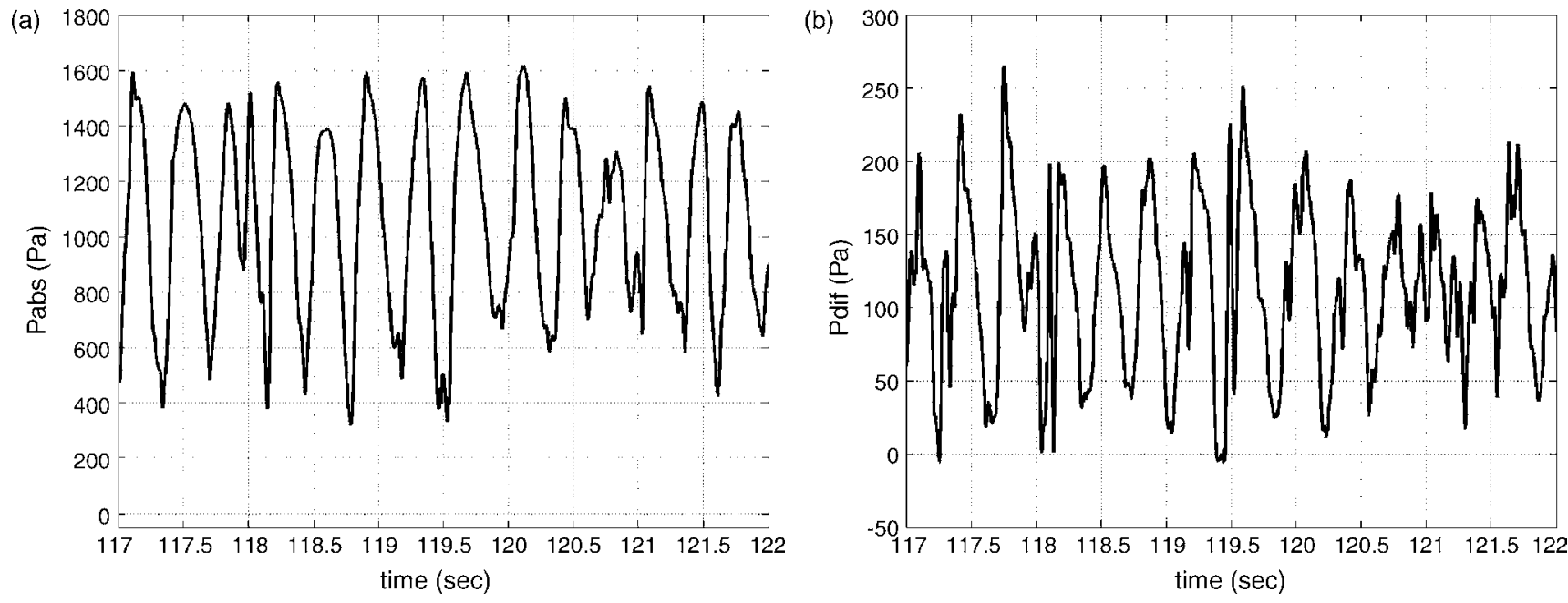

Fig. 2 - Absolute (a) and differential (b) pressure signals.

the frequency $f$ representing the overall behaviour of the bed is obtained from the equation by Baskakov et al. (1986):

$f=\frac{1}{\pi} \sqrt{\frac{g}{H_{\mathrm{mf}}}}$

To derive this expression, Baskakov et al. (1986) considered that the major effect on pressure fluctuations is exerted by the bubbles that rise from the bed and burst to the surface.

Therefore, a complete signal pressure can be simulated as

$P_{\text {signal }}(t)=\rho_{\mathrm{P}}\left(1-\varepsilon_{\mathrm{mf}}\right) g(H-z)+P_{\mathrm{f}}(t)$

where the first term is the mean hydrostatic pressure seen by a sensor placed at a distance $z$ from the distributor and the second term is the fluctuating component given in Eq. (4). The voidage $\varepsilon_{\mathrm{mf}}$ is the one predicted at minimum fluidizing conditions (Kunii and Levenspiel, 1991).

\section{Experiments}

Pressure fluctuations are commonly measured with the use of sensitive pressure transducers connected to a pressure probe either flush with the inner wall of the column or immersed in the fluidized bed. However, the measurements can be difficult to interpret. Fan et al. (1981) proposed using single pressure transducers to describe fluidized beds while Bi et al. (1995) used several differential transducers to describe the nature of the bed.

In the present work, experimental measurements have been carried out in two different beds. The first test rig (rig A) is a transparent cylinder with $192 \mathrm{~mm}$ i.d. and a height of $0.8 \mathrm{~m}$. The bed was filled with Geldart B silica particles with a mean diameter $d_{p}=500 \mu \mathrm{m}$ and a density $\rho_{p}=2600 \mathrm{~kg} / \mathrm{m}^{3}$. The settled bed height was $20 \mathrm{~cm}$. The pressure probes were mounted at the bed axis at $12 \mathrm{~cm}, 13 \mathrm{~cm}$ and $14 \mathrm{~cm}$ from the distributor plate. The pressure oscillations were measured with Omega PX piezoresistive differential pressure transmitters. The sensors were mounted on a $3 \mathrm{~mm}$ i.d. steel probe and silicone connecting tubing with a total length of about $2 \mathrm{~m}$. The data were recorded with a 12 bits data acquisition board (ICP DAS PCI $1802 \mathrm{H}$ ) assembled in a PC. The sample frequency was $200 \mathrm{~Hz}$. Fig. 2 represents the corresponding absolute (Fig. 2a) and differential pressure (Fig. 2b) measured signals in the bubbling regime, at a superficial gas velocity $U$ in excess of the minimum velocity $U_{\mathrm{mf}}$ equal to $U=1.3 U_{\mathrm{mf}}\left(U_{\mathrm{mf}}=0.38 \mathrm{~m} / \mathrm{s}\right)$.

A second set of measurements have been taken in a second test rig (rig B) consisting on a cylinder of $300 \mathrm{~mm}$ i.d. bed, with pressure probes placed flush with the column wall at $z=8 \mathrm{~cm}, 11 \mathrm{~cm}$ and $15 \mathrm{~cm}$. The bed was filled with silica sand $\left(d_{\mathrm{P}}=150 \mu \mathrm{m}, \rho_{\mathrm{P}}=2600 \mathrm{~kg} / \mathrm{m}^{3}\right)$ and the settled bed height was $20 \mathrm{~cm}$.

\section{Results and discussion}

The pressure signal records simulated with the present model for the same conditions of the measurements described for rig A are compared in Fig. 3. Differential pressure has been calculated as the difference between the two pressure values $P_{\text {signal }}(t)$ in Eq. (8) at two different positions.

Both absolute and differential pressure values are shown for an enlarged time period of Fig. 2.

The passage of three bubbles can be identified in the experimental measurements and in the simulated records: one of the bubbles passes across the sensors giving a value of zero in the differential sensor (119.5 s) and the two other bubbles are passing the probe with a certain eccentricity (Ramayya et al., 1996).

A close agreement between experimental and simulated records is found. It can be observed that differential dualsensors are more suitable than single point sensors to detect bubble passage and measure bubble parameters. As explained before pressure measurements from a single probe reflect more global phenomena in the bed as opposed to the differential probes that reflect phenomena occurring between the probe ports.

\subsection{Standard deviation of pressure fluctuations}

Fig. 4 shows the simulated standard deviation of differential and absolute pressure fluctuations against the gas velocity $U$, varying the probe height. The pressure has been calculated according to Eq. (8) where the fluctuating component $P_{\mathrm{f}}(t)$ is obtained for particles of diameter $d_{p}=550 \mu \mathrm{m}$ and density $\rho_{\mathrm{p}}=2600 \mathrm{~kg} / \mathrm{m}^{3}$, in a bed of height $\mathrm{H}=22 \mathrm{~cm}$, and with a minimum fluidization velocity $U_{\mathrm{mf}}=0.44 \mathrm{~m} / \mathrm{s}$. Differential pressure has been calculated as the difference between the two pressures values at two different positions $z_{1}$ and $z_{2}$. 

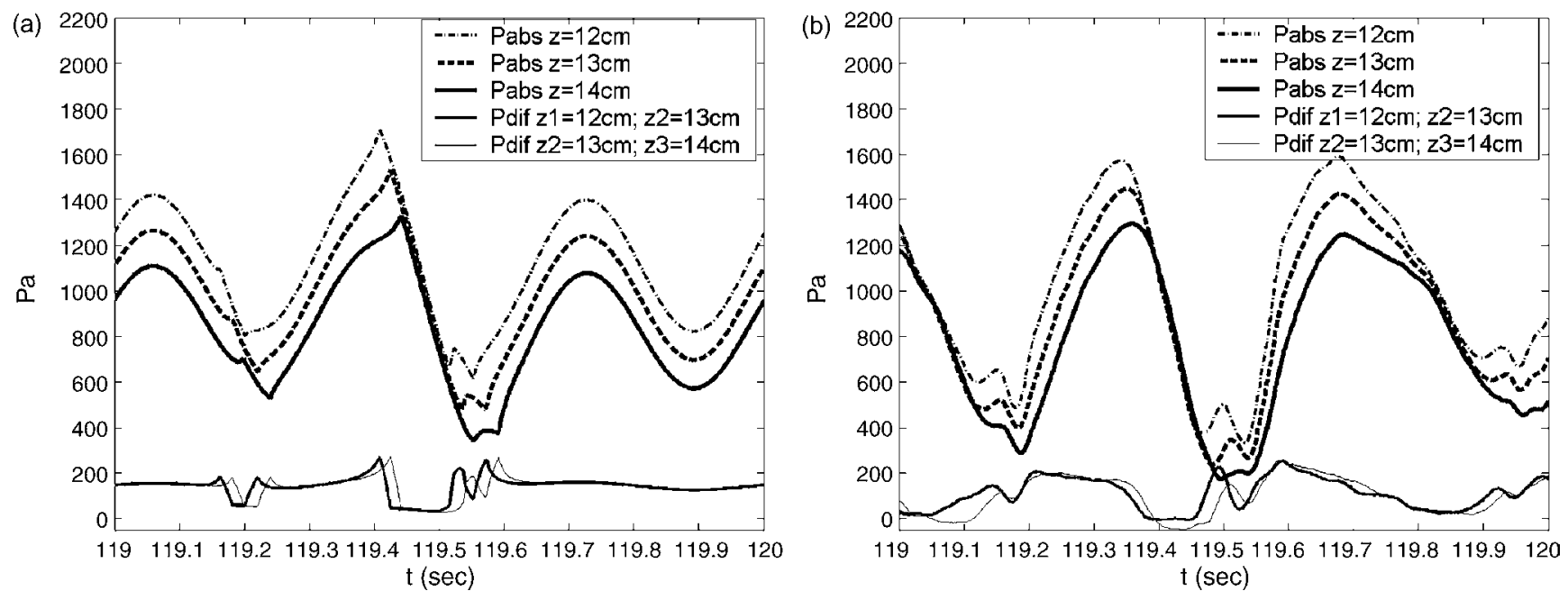

Fig. 3 - Absolute and differential pressure records: model (a) and the corresponding measurements (b).

Standard deviation of absolute pressure fluctuation increases linearly with excess gas, when the first term in Eq. (4) is large compared to pressure fluctuations caused by a bubble passage. It can be observed in Fig. 4 that there is a low dependency of probe position on the absolute pressure measurement.

On the other hand, for differential pressure measurements, the standard deviation increases with excess gas, but it is found to be strongly dependent on the distance between ports and the probe height above the distributor. As the distance between ports of the differential probe increases, the local passage of the bubble becomes less important, and the differential probe tends to the absolute probe behaviour.

When the distance between probes is lower than the expected bubble diameter for a given height, the standard deviation of differential pressure fluctuations as a function of air velocity correlates well with the diameter, as shown in Fig. 5. In this figure, the evolution of bubble diameter $D_{B}$ with height $z$, for different excess gas velocities is represented (Fig. 5a) along with the calculated relation $\sigma / D_{\text {B }}$ (Fig. 5b) for different probes heights and separation between ports. The expected bubble diameter for a given height has been calculated using Eq. (3). For low separation between ports, $\sigma / D_{\mathrm{B}}$ remains constant, at any excess gas: the diameter in all the range is larger than the probe separation and the fluctuation represents the bubble diameter behaviour. As the separation increases (e.g. $S=3 \mathrm{~cm}$ ), this holds only for higher excess gas. If the separation between ports increases still, then the fluctuation (represented by $\sigma$ ) does not follow only the diameter behaviour but the contribution of the first term in Eq. (4), i.e. global phenomena in the bed, becomes more important.

That is in agreement with Sitnai (1982) and Ramayya et al. (1996) who recommended a maximum distance between ports for a correct measurement of the bubble characteristic length. Nevertheless, the experimental measurements they present were conducted injecting one controlled bubble in a bed at incipient fluidization condition, and therefore the general oscillation of the bed was not present.

The method of the standard deviation of pressure fluctuations to predict the minimum fluidization velocity (Puncochar et al., 1985), has been extensively used in the literature. According with the shown results this holds for absolute measurements and may also be used with differential sensors, as long as the distance between ports is large enough. This is for example, the case of the measurements of Felipe and Rocha (2007) who reported absolute and differential pressure measurements in a bubbling fluidized bed. Fig. 6 shows values of
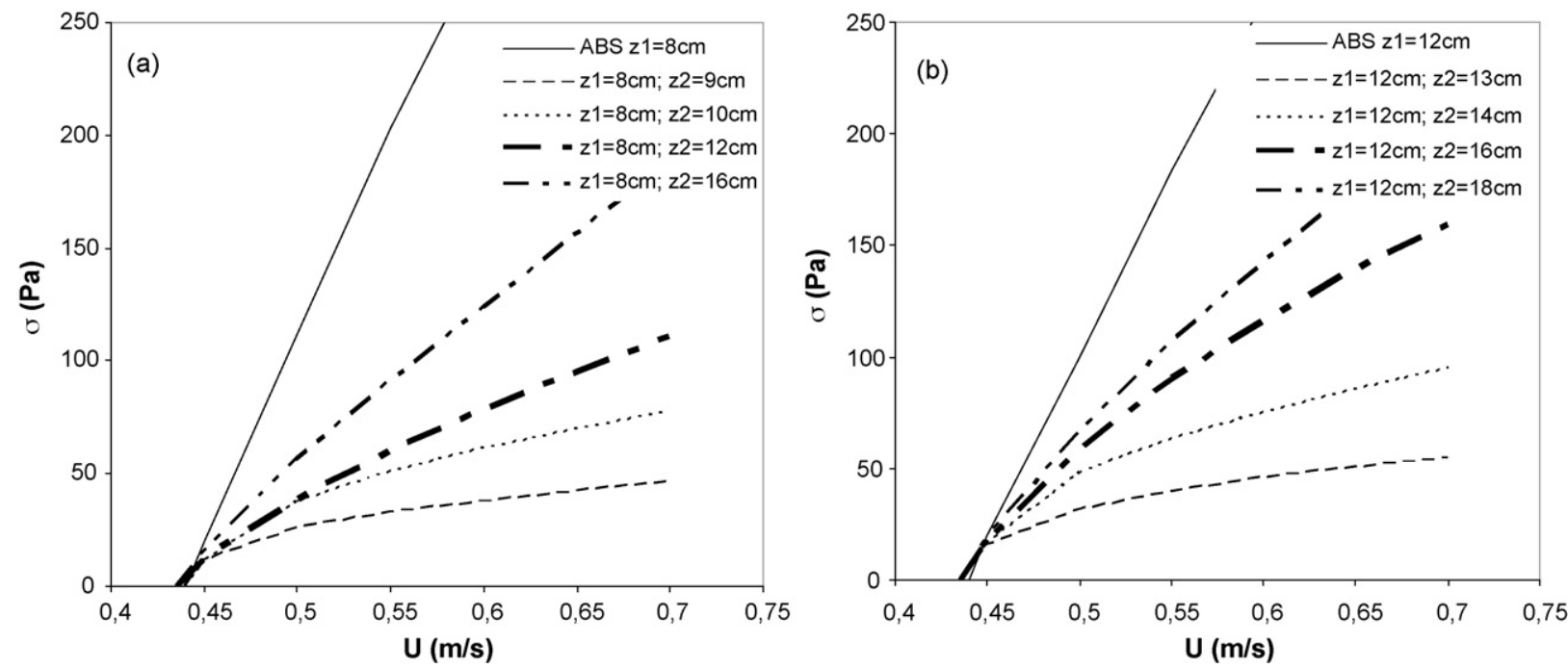

Fig. 4 - Standard deviation of absolute and differential pressure fluctuations calculated from the simulated pressure signal Eq. (8) - at (a) $z_{1}=8 \mathrm{~cm}$; (b) $z_{1}=12 \mathrm{~cm}$ and different distances between pressure ports. 

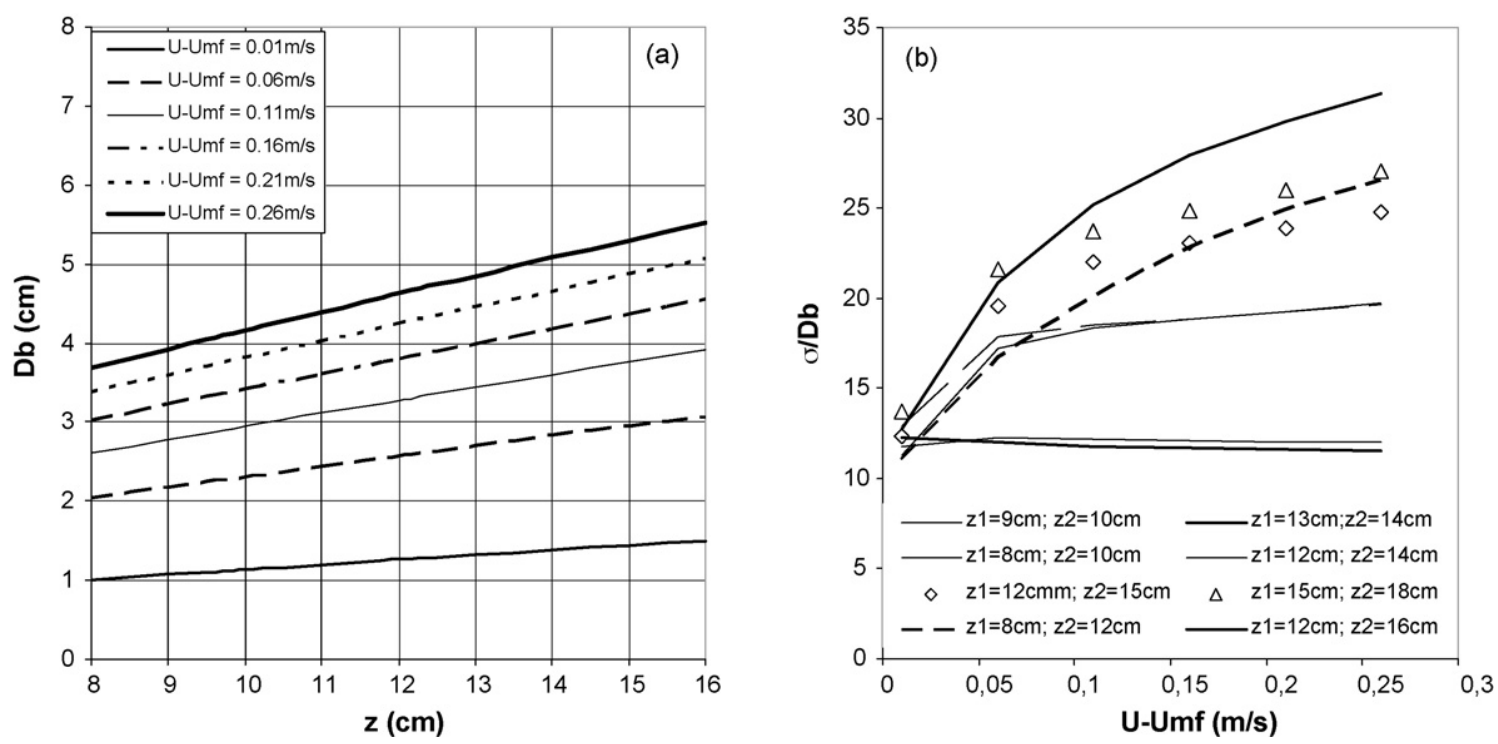

Fig. 5 - (a) Expected bubble diameter $D_{B}$. (b) Calculated $\sigma / D_{B}$ at different bed heights $z$ and excess gas conditions.

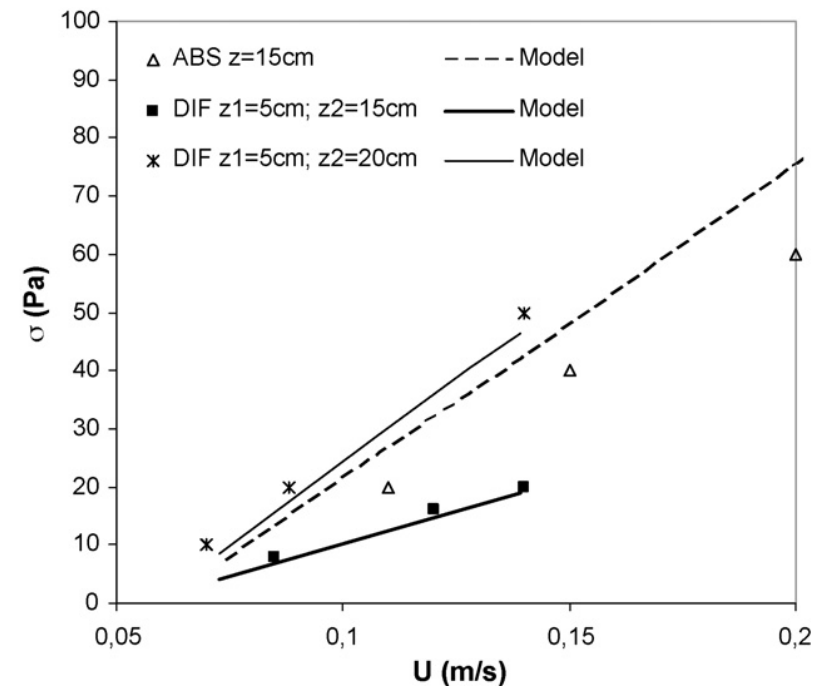

Fig. 6 - Standard deviation of pressure fluctuation against superficial gas velocity $U(\mathrm{~m} / \mathrm{s})$ for differential and absolute pressure measurements from work of Felipe and Rocha (2007).

$\sigma$ from their experiments and those predicted by the present model. In this case, the distance between the differential pressure ports is large enough and then standard deviation trend for differential and absolute measurements is similar and a linear increase with the excess gas is found.

The predicted evolution of the standard deviation of absolute and differential pressure fluctuations as a function of excess gas has been validated with two set of measurements. Experimental results for rig A are shown in Fig. 7.

The model and the experimental values follow the same trend.

Fig. 8 depicts the standard deviation of pressure fluctuations against the gas velocity for the second set-up (rig B). It can be seen that experimental data follow the linear relationship predicted by the model for the absolute pressure fluctuations. It can also be observed that as predicted, the differential pressure probe with a higher distance between ports shows a behaviour that resembles the absolute measurements.

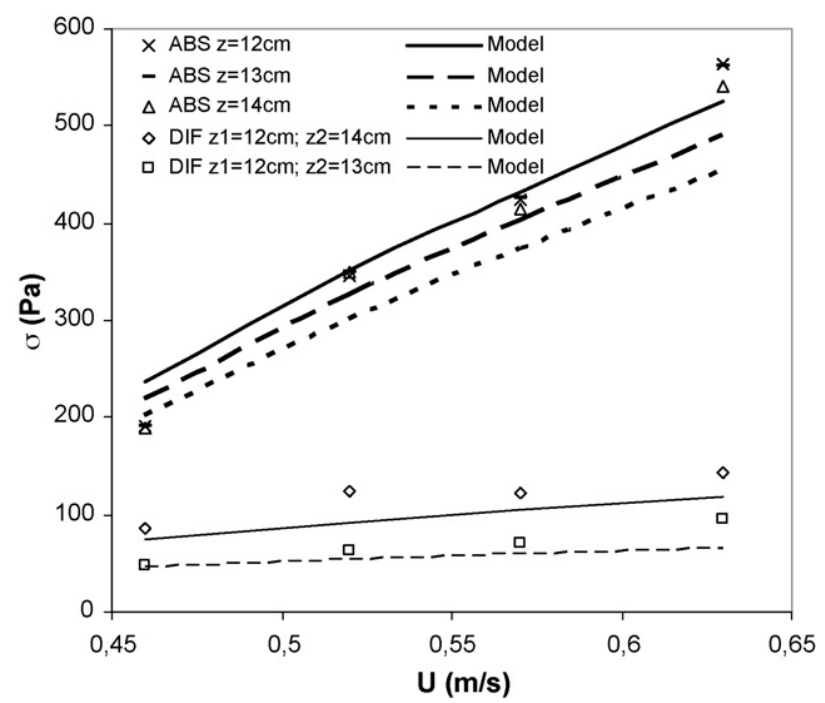

Fig. 7 - Standard deviation $\sigma$ of absolute and differential pressure measurements carried out in rig $A$ against gas velocity $U$.

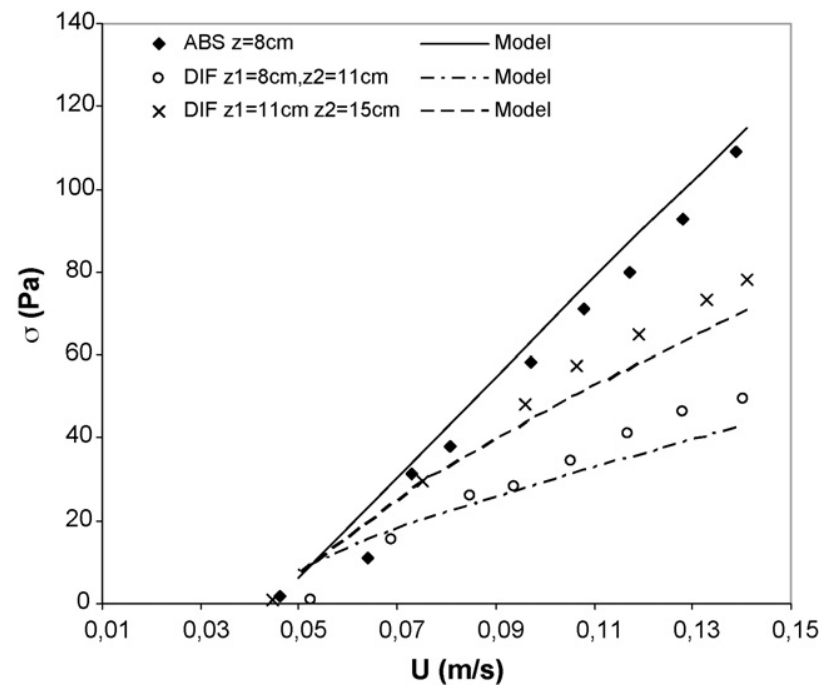

Fig. 8 - Standard deviation $\sigma$ of absolute and differential pressure measurements carried out in rig B against gas velocity $U$. 


\section{Conclusions}

A simple method for the simulation of the pressure signal in a bubbling fluidized bed for group B particles is presented. The corresponding standard deviation of the simulated signal compares well with experimental results. The use of standard fluctuations of differential pressure to determine the minimum fluidization velocity can be achieved provided that the separation between probes is larger than the expected diameter for the given measurement position.

\section{Acknowledgements}

This work has been supported by the National Energy Programme of the Spanish Ministry of Education under the project number ENE2006-01401 and by the Universidad Carlos III de Madrid (CCG06-UC3M/ENE-0764).

\section{References}

Alzahrani, A.A. and Wali, M.M.N., 1993, A study of pressure drop fluctuations in a gas-solids fluidized bed. Powder Technology, 76: 185-189.

Bai, B., Gheorghiu, S., van Ommen, J.R., Nijenhuis, J. and Coppens, M.-O., 2005, Characterization of the void size distribution in fluidized beds using statistics of pressure fluctuations. Powder Technology, 160: 81-92.

Baskakov, A.P., Tuponogov, V.G. and Filippovsky, N.F., 1986, A study of pressure fluctuations in a bubbling fluidized bed. Powder Technology, 45: 113-117.

Bi, H.T., Grace, J.R. and Zhu, J., 1995, Propagation of pressure waves and forced oscillations in gas-solid fluidized beds and their influence on diagnostics of local hydrodynamics. Powder Technology, 82: 239-253.

Bi, H.T., 2007, A critical review of the complex pressure fluctuation phenomenon in gas-solids fluidized beds. Chemical Engineering Science, 62: 3473-3493.

Chen, A.H. and Bi, H.T., 2003, Pressure fluctuations and transition from bubbling to turbulent fluidization. Powder Technology, 133(1-3): 237-246.

Clift, R. and Grace, J.R., 1985, in Davidson, J.F., Clift, R., \& Darton, R.C. (eds) (Academic Press, London), pp. 73-132.

Croxford, A.J., Harrison, A.J.L. and Gilbertson, M.A., 2005, The optimization of pressure measurements for the control of bubbling fluidised beds. International Journal of Chemical Reactor Engineering, 3(A39)

Davidson, J.F. and Harrison, D., (1963). Fluidized particles. (Cambridge University Press, New York USA), pp. 63-79

Darton, R.C., LaNauze, R.D., Davidson, J.F. and Harrison, D., 1977, Bubble-growth due to coalescence in fluidized-beds. Transactions of the institution of chemical engineers, 55(4): 274-280.

Fan, L.T., Ho, T.-C., Hiraoka, S. and Walawender, W.P., 1981, Pressure fluctuations in a fluidized bed. AIChE Journal, 27(3): 388-396.

Felipe, C.A.S. and Rocha, S.C.S., 2007, Prediction of minimum fluidization velocity of gas-solid fluidized beds by pressure fluctuation measurements-analysis of the standard deviation methodology. Powder Technology, 174: 104-113.

Hiraoka, S., Shin, S.H., Fan, L.T. and Kim, K.C., 1984, Pressure fluctuations in a gas-solids fluidized bed-effect of external noise and bubble residence time distribution. Powder Technology, 38: 125-143.

Hiraoka, S., Kim, K.C., Shin, S.H. and Fan, L.T., 1986, Properties of pressure fluctuations in a gas-solids fluidized bed under a free bubbling condition. Powder Technology, 45: 245-265.

Hong, S.C., Jo, B.R., Doh, D.S. and Choi, C.S., 1990, Determination of minimum fluidization velocity by the statistical analysis of pressure fluctuations in a gas-solid fluidized bed. Powder Technology, 60: 215-221.

Johnsson, F., Zijerveld, R.C., Schouten, J.C., van den Bleek, C.M. and Leckner, B., 2000, Characterization of fluidization regimes by time-series analysis of pressure fluctuations. International Journal of Multiphase Flow, 26: 663-715.

Kunii, D. and Levenspiel, O., (1991). Fluidization engineering. (Butterworth-Heinemann), pp. 61-94

Lirag, R.C., Jr. and Littman, H., 1971, Statistical study of the pressure fluctuations in a fluidized bed. AIChE Symposium Series, 116(67): 11-22.

Puncochar, M., Drahos, J., Cermak, J. and Selucky, K., 1985, Evaluation of minimum fluidizing velocity in gas fluidized bed from pressure fluctuations. Chemical Engineering Communications, 35: 81-87.

Puncochar, M. and Drahos, J., 2005, Origin of pressure fluctuations in fluidized beds. Chemical Engineering Science, 60: 1193-1197.

Ramayya, A.V., Venkateshan, S.P. and Kolar, A.K., 1996, Estimation of bubble parameters from differential pressure measurements in gas-fluidized beds. Powder Technology, 87(2): 113-126.

Rowe, P.N. and Masson, H., 1981, Interaction of bubbles with probes in gas fluidised beds. Transactions of the Institution of Chemical Engineers, 59(3): 177-185.

Roy, R. and Davidson, J.F., 1989, Similarity between gas-fluidized beds at elevated temperature and pressure, in Fluidization VI, Grace, and Shemilt, Shemilt, (eds)

Sitnai, O., 1982, Utilization of the pressure differential records from gas-fluidized beds with internals for bubble parameters determination. Chemical Engineering Science, 37(7): 1059-1066.

Svoboda, K., Cermak, J., Hartman, M., Drahos, J. and Selucky, K., 1983, Pressure fluctuations in gas-fluidized beds at elevated temperatures. Industrial \& Engineering Chemistry Process Design and Development, 22(3): 514-520.

Svoboda, K., Cermak, J., Hartman, M., Drahos, J. and Selucky, K., 1984, Influence of particle size on the pressure fluctuations and slugging in a fluidized bed. AIChE Journal, 30(3): 513-517.

Talmor, E. and Benenati, R.F., 1963, Solids mixing and circulation in gas fluidized beds. AIChE Journal, 9(4): 536-540.

van der Schaaf, J., Schouten, J.C., Johnsson, F. and van den Bleek, C.M., 2002, Non-intrusive determination of bubble and slug length scales in fluidized beds by decomposition of the power spectral density of pressure time series. International Journal of Multiphase Flow, 28: 865-880.

van Ommen, J.R., van der Schaaf, J., Schouten, J.C., van Wachem, B.G.M., Coppens, M.-O. and van den Bleek, C.M., 2004, Optimal placement of probes for dynamic pressure measurements in large scale fluidized beds. Powder Technology, 139: 264-276.

Verloop, J. and Heertjes, P.M., 1974, Periodic pressure fluctuations in fluidized beds. Chemical Engineering Science, 29: 1035-1042.

Wilkinson, D., 1995, Determination of minimum fluidization velocity by pressure fluctuation measurement. The Canadian Journal of Chemical Engineering, 73: 562-565. 